ORIGINAL ARTICLE

\title{
Associations between ambient, personal, and indoor exposure to fine particulate matter constituents in Dutch and Finnish panels of cardiovascular patients
}

\author{
N A H Janssen, T Lanki, G Hoek, M Vallius, J J de Hartog, R Van Grieken, J Pekkanen, \\ B Brunekreef
}

Occup Environ Med 2005;62:868-877. doi: 10.1136/oem.2004.016618

See end of article for authors' affiliations

Correspondence to:

Dr N A H Janssen, National Institute for Public Health and the

Environment (RIVM),

Center for Environmental Health Research, PO Box 1, 3720 BA Bilthoven, the Netherlands; nicole. janssen@rivm.nl

Accepted 16 June 2005

\begin{abstract}
Aims: To assess the relation between ambient, indoor, and personal levels of $\mathrm{PM}_{2.5}$ and its elemental composition for elderly subjects with cardiovascular disease.

Methods: In the framework of a European Union funded study, panel studies were conducted in Amsterdam, the Netherlands and Helsinki, Finland. Outdoor PM 2.5 concentrations were measured at a fixed site. Each subject's indoor and personal $\mathrm{PM}_{2.5}$ exposure was measured biweekly for six months, during the 24 hour period preceding intensive health measurements. The absorbance of $\mathrm{PM}_{2.5}$ filters was measured as a marker for diesel exhaust. The elemental content of more than $50 \%$ of the personal and indoor samples and all corresponding outdoor samples was measured using energy dispersive $x$ ray fluorescence.

Results: For Amsterdam and Helsinki respectively, a total of 225 and 238 personal, and 220 and 233 indoor measurements, were analysed from 36 and 46 subjects. For most elements, personal and indoor concentrations were lower than and highly correlated with outdoor concentrations. The highest correlations (median $r>0.9$ ) were found for sulfur and particle absorbance, which both represent fine mode particles from outdoor origin. Low correlations were observed for elements that represent the coarser part of the $\mathrm{PM}_{2.5}$ particles $(\mathrm{Ca}, \mathrm{Cu}, \mathrm{Si}, \mathrm{Cl})$.

Conclusions: The findings of this study provide support for using fixed site measurements as a measure of exposure to particulate matter in time series studies linking the day to day variation in particulate matter to the day to day variation in health endpoints, especially for components of particulate matter that are generally associated with fine particles and have few indoor sources. The high correlation for absorbance of $\mathrm{PM}_{2.5}$ documents that this applies to particulate matter from combustion sources, such as diesel vehicles, as well.
\end{abstract}

$\mathrm{N}$ umerous studies have demonstrated associations between day to day variations in ambient particulate matter concentrations and day to day variations in health endpoints such as mortality..$^{1-3}$ Most studies have used ambient particulate matter concentrations measured at central monitoring sites, as exposure variables. The plausibility of the epidemiological evidence has been challenged on the grounds that these ambient measurements may not properly reflect personal exposures. This criticism was supported by studies conducted in the 1980s to early 1990s that found that personal exposures to particulate matter were much higher than and poorly correlated with ambient concentrations. ${ }^{45} \mathrm{~A}$ series of studies conducted in the Netherlands has shown that the correlation between ambient $\mathrm{PM}_{10}$ and personal exposure is much stronger if the analysis is conducted longitudinally (that is, within subjects over time), which is the relevant correlation for time series studies. The time series correlation between ambient and personal fine particles among a small group of primary school children, was even higher. ${ }^{6-8}$ Several recent studies conducted in the US and Canada examined the longitudinal correlations for potentially sensitive subjects such as elderly and/or patients with chronic obstructive pulmonary disease (COPD) ${ }^{9-13}$ These studies have shown variable results, with median individual correlation coefficients $(r)$ ranging from 0.25 for 15 non-smoking elderly in Baltimore, MD in the winter of $1999^{\circ}$ to 0.81 for 21 elderly also in Baltimore, MD in the summer of $1998 .{ }^{11}{ }^{12}$
Personal particulate matter exposure includes particles both from ambient origin and indoor sources. To validate the use of central site monitoring as a proxy for personal exposure, we need to determine the correlation between personal exposure to particles from ambient origin and ambient concentrations. ${ }^{14}$ One approach to achieve this is to use indicator elements that have little or no indoor sources. Several studies have used sulfur (S) or sulfate for this purpose. ${ }^{9-12}$ All of these studies reported higher correlations for sulfate than for $\mathrm{PM}_{2.5}$ mass. This suggests that ambient fine particle concentrations could be adequate proxies for estimating personal exposure to fine particles from ambient origin in time series studies.

While the health effects of particulate matter are now generally accepted, the mechanism and the fraction of particulate matter responsible for the observed effects is less known. Some of the major current hypotheses for the responsible particle fraction are soluble transition metals, organic carbon compounds, strong aerosol acidity and ultrafine particles. ${ }^{15}$ Other studies suggest that particles from specific sources, especially traffic related particles, are specifically associated with health effects. Laden $e t$ al ${ }^{16}$ used data on outdoor elemental composition of $\mathrm{PM}_{2.5}$ combined

Abbreviations: $A B S$, absorption coefficient; $C O P D$, chronic obstructive pulmonary disease; $C V$, coefficient of variation; CVD, cardiovascular disease; ED-XRF, energy dispersive $x$ ray fluorescence; TEO, trace element oxides 
with factor analysis to assign measured $\mathrm{PM}_{2.5}$ concentrations to particles from different sources. The approach uses indicator elements for sources (for example, $\mathrm{Pb}$ for traffic, Si for crustal sources). Little information is available on the time series correlation between personal exposure to particles from specific sources and ambient concentrations, or on the correlation between personal and ambient elemental (metal) concentrations.

We therefore studied the time series correlation between ambient, indoor, and personal $\mathrm{PM}_{2.5}$ elemental concentrations in panels of elderly subjects with cardiovascular disease (CVD). Correlations for $\mathrm{PM}_{2.5}$ mass concentrations in these same panels have been published previously. ${ }^{17}$

\section{METHODS}

\section{Study design}

The study was conducted in the framework of a European Union funded panel study on the effects of exposure to outdoor fine and ultrafine particles on cardiovascular and respiratory health of elderly subjects with CVD (ULTRA study). The present personal exposure study was conducted in Amsterdam, the Netherlands, and in Helsinki, Finland, in the winter/spring of 1998/1999. A complete description of the study design and population characteristics has been published previously. ${ }^{17}{ }^{18}$ Briefly, 24 hour average personal and indoor $\mathrm{PM}_{2.5}$ exposures were measured biweekly for six months in 84 (37 in Amsterdam and 47 in Helsinki) nonsmoking elderly (age 50-84 years) with CVD. Outdoor concentrations were measured daily at a fixed site. In addition to gravimetric analyses, reflectance of all personal, indoor, and outdoor $\mathrm{PM}_{2.5}$ filters was measured as a marker for elemental carbon, a major part of diesel soot. ${ }^{19}$ Elemental composition of part of the personal and indoor samples and all outdoor samples was measured using energy dispersive $x$ ray fluorescence (ED-XRF). Field measurements took place from 2 November 1998 to 18 June 1999 in Amsterdam and from 1 November 1998 to 30 April 1999 in Helsinki.

\section{Sampling methods}

In both cities, the same sampling methods and standard operating procedures were used. Details about the sampling methods have been published elsewhere. ${ }^{17}$ Briefly, personal, indoor, and outdoor $\mathrm{PM}_{2.5}$ was measured using $\mathrm{PM}_{2.5}$ GK2.05 cyclones (BGI Inc, Waltham, MA, USA) for personal sampling and the Harvard Impactor (ADE Inc, Naples, MA, USA) for indoor and outdoor sampling. Indoor samples were

\begin{tabular}{|c|c|c|c|c|c|c|}
\hline & \multicolumn{3}{|c|}{ Amsterdam } & \multicolumn{3}{|l|}{ Helsinki } \\
\hline & $\begin{array}{l}\text { Indoor } \\
(n=220)\end{array}$ & $\begin{array}{l}\text { Outdoor } \\
(n=228)\end{array}$ & $\begin{array}{l}\text { Personal } \\
(n=225)\end{array}$ & $\begin{array}{l}\text { Indoor } \\
(n=233)\end{array}$ & $\begin{array}{l}\text { Outdoor } \\
(n=168)\end{array}$ & $\begin{array}{l}\text { Personal } \\
(n=238)\end{array}$ \\
\hline$S$ & $100 \%$ & $100 \%$ & $100 \%$ & $100 \%$ & $100 \%$ & $100 \%$ \\
\hline $\mathrm{Zn}$ & $100 \%$ & $100 \%$ & $99 \%$ & $100 \%$ & $100 \%$ & $100 \%$ \\
\hline $\mathrm{Fe}$ & $100 \%$ & $100 \%$ & $100 \%$ & $100 \%$ & $100 \%$ & $100 \%$ \\
\hline K & $100 \%$ & $100 \%$ & $100 \%$ & $100 \%$ & $100 \%$ & $98 \%$ \\
\hline $\mathrm{Ca}$ & $100 \%$ & $100 \%$ & $100 \%$ & $100 \%$ & $99 \%$ & $97 \%$ \\
\hline $\mathrm{Cu}$ & $100 \%$ & $100 \%$ & $98 \%$ & $100 \%$ & $98 \%$ & $100 \%$ \\
\hline $\mathrm{Ni}$ & $97 \%$ & $100 \%$ & $83 \%$ & $100 \%$ & $99 \%$ & $55 \%$ \\
\hline $\mathrm{Pb}$ & $89 \%$ & $96 \%$ & $75 \%$ & $100 \%$ & $83 \%$ & $88 \%$ \\
\hline $\mathrm{Cl}$ & $80 \%$ & $88 \%$ & $58 \%$ & $85 \%$ & $71 \%$ & $54 \%$ \\
\hline $\mathrm{Mn}$ & $93 \%$ & $95 \%$ & $66 \%$ & $91 \%$ & $95 \%$ & $45 \%$ \\
\hline $\mathrm{Si}$ & $78 \%$ & $42 \%$ & $52 \%$ & $89 \%$ & $65 \%$ & $89 \%$ \\
\hline V & $40 \%$ & $63 \%$ & $8 \%$ & $62 \%$ & $75 \%$ & $52 \%$ \\
\hline Al & $52 \%$ & $41 \%$ & $52 \%$ & $24 \%$ & $64 \%$ & $20 \%$ \\
\hline $\mathrm{Br}$ & $47 \%$ & $71 \%$ & $9 \%$ & $30 \%$ & $42 \%$ & $46 \%$ \\
\hline $\mathrm{Cr}$ & $18 \%$ & $16 \%$ & $3 \%$ & $9 \%$ & $8 \%$ & $30 \%$ \\
\hline $\mathrm{Ti}$ & $16 \%$ & $19 \%$ & $2 \%$ & $12 \%$ & $15 \%$ & $32 \%$ \\
\hline
\end{tabular}

taken in the living room at about one metre height. Outdoor $\mathrm{PM}_{2.5}$ concentrations were measured at fixed monitoring sites, representing urban background levels.

In both centres, filters were weighed using a Mettler MT5 micro-balance (Mettler-Toledo, Greifensee, Switzerland) with $1 \mu \mathrm{g}$ reading. Particle reflectance was measured using EEL 43 reflectometers, and transformed into an absorption coefficient (ABS) according to ISO 9835. ${ }^{20}$ This method is based on the old black smoke protocol, ${ }^{21}$ with the exception of the particle cut size and filter material. Although the black smoke method involves a transformation from reflectance units into mass concentrations, these calculated mass concentrations are considered unreliable. ${ }^{22} \mathrm{ABS}$ is therefore expressed in $\mathrm{m}^{-1} \times 10^{-5}$.

Measurements of elemental composition using ED-XRF Elemental composition was measured using ED-XRF. Measurements were conducted by the Department of Chemistry of the University of Antwerp, Belgium, using an automated Tracor Spectrace 5000 ED-XRF system (Tracor $x$ ray, Austin, TX, USA). Details have been published elsewhere. ${ }^{23}$

Only samples for which both the personal and indoor measurements, as well as the corresponding outdoor measurement, were successfully collected were considered eligible for $x$ ray fluorescence analyses. This was the case for 337 pairs of personal and indoor samples in Amsterdam and 310 pairs in Helsinki. In both countries, one subject who had fewer than four valid pairs was excluded. For each subject, five (Helsinki) or six (Amsterdam) pairs of personal and indoor samples were randomly chosen. The difference between the two countries is caused by, on the one hand, the higher number of subjects in Helsinki (46 compared with 36 in Amsterdam) and, on the other hand, the longer observation period in Amsterdam (requiring a larger proportion of the available budget for analysis of outdoor samples). Out of the remaining, unselected, samples additional pairs of personal and indoor samples were randomly chosen until the total number of budgeted analysis was reached. This resulted in 4-7 pairs per subject (for one subject only four pairs of samples were available). The total numbers of samples and duplicates analysed in both cities are included in table 1 and 2, respectively. In both cities, the difference between the number of personal and indoor samples is caused by the fact that one married couple participated, for which on five days the personal samples of both partners were selected, resulting in five fewer indoor samples that had to be analysed.

For each type of sample (personal, indoor, and outdoor), 10 field blanks per city were analysed. Median field blank values were subtracted from all sample values. Medians were used instead of means because field blank values were not normally distributed for all elements.

For each element the uncertainty per sample was calculated. This uncertainty is not only affected by analysis variables, such as calibration and system stability, but also by the concentration of the element in the sample. Uncertainty limits, calculated as three times the uncertainty, thus changed from sample to sample for each element, and increased with increasing concentrations. With the exception of the field blanks, measurements below the uncertainty limit were not reported by the Antwerp laboratory. We therefore set these measurements at two thirds of the uncertainty limit of the lower 25th percentile. We chose the 25th percentile instead of, for example, the average uncertainty limit of all reported values, because we expected the undetected values to be in the lower end of the distribution. Measurement that yielded negative concentrations after subtraction of the median field blank were set to zero. For 


\begin{tabular}{|c|c|c|c|c|c|c|c|c|c|c|c|c|}
\hline & & \multicolumn{5}{|c|}{ Amsterdam } & \multicolumn{6}{|c|}{ Helsinki } \\
\hline & \multicolumn{2}{|c|}{ Indoor $(n=10)$} & \multicolumn{2}{|c|}{$\begin{array}{l}\text { Outdoor } \\
(n=10)\end{array}$} & \multicolumn{2}{|c|}{$\begin{array}{l}\text { Personal } \\
(n=5)\end{array}$} & \multicolumn{2}{|c|}{ Indoor $(n=10)$} & \multicolumn{2}{|c|}{$\begin{array}{l}\text { Outdoor } \\
(n=7)\end{array}$} & \multicolumn{2}{|c|}{ Personal $(n=7)$} \\
\hline & $\bar{n}$ & Median & $\bar{n}$ & Median & $\bar{n}$ & Median & $n$ & Median & $n$ & Median & $\bar{n}$ & Median \\
\hline $\mathrm{PM}_{2.5}$ & 10 & 3.6 & 10 & 1.7 & 5 & 13.0 & 10 & 6.4 & 7 & 7.8 & 7 & 7.0 \\
\hline Abs & 10 & 4.5 & 10 & 3.3 & 5 & 10.7 & 10 & 3.3 & 7 & 4.7 & 7 & 5.7 \\
\hline$S$ & 10 & 2.5 & 10 & 2.9 & 5 & 4.5 & 10 & 3.1 & 7 & 2.5 & 7 & 1.3 \\
\hline $\mathrm{Zn}$ & 10 & 3.2 & 10 & 3.0 & 5 & 18.4 & 10 & 6.4 & 7 & 9.7 & 7 & 3.1 \\
\hline $\mathrm{Fe}$ & 10 & 4.7 & 10 & 9.5 & 5 & 16.4 & 10 & 11.6 & 7 & 35.4 & 7 & 2.6 \\
\hline $\mathrm{Ni}$ & 10 & 4.3 & 10 & 33.6 & 5 & 70.8 & 10 & 19.7 & 7 & 3.9 & 3 & 35.7 \\
\hline $\mathrm{Mn}$ & 10 & 7.5 & 9 & 10.7 & 5 & 39.0 & 8 & 22.1 & 6 & 41.2 & 6 & 141.4 \\
\hline V & 5 & 24.4 & 9 & 13.2 & 0 & & 8 & 17.4 & 3 & 15.1 & 1 & 32.5 \\
\hline $\mathrm{K}$ & 10 & 3.2 & 10 & 5.0 & 5 & 4.1 & 10 & 3.7 & 7 & 30.0 & 7 & 11.6 \\
\hline $\mathrm{Ca}$ & 10 & 4.9 & 10 & 10.0 & 5 & 2.7 & 10 & 7.5 & 7 & 46.2 & 7 & 2.9 \\
\hline $\mathrm{Cu}$ & 10 & 4.0 & 10 & 43.8 & 5 & 34.0 & 10 & 10.3 & 7 & 64.3 & 7 & 6.1 \\
\hline $\mathrm{Si}$ & 8 & 11.7 & 3 & 12.1 & 4 & 22.3 & 10 & 13.6 & 7 & 56.4 & 6 & 23.9 \\
\hline $\mathrm{Cl}$ & 8 & 9.3 & 8 & 23.0 & 3 & 14.5 & 8 & 5.1 & 1 & 51.4 & 5 & 6.9 \\
\hline $\mathrm{Pb}$ & 9 & 40.5 & 10 & 50.1 & 4 & 20.3 & 10 & 14.2 & 7 & 84.6 & 6 & 95.2 \\
\hline Al & 4 & 89.7 & 2 & 26.0 & 1 & 141.4 & 3 & 141.4 & 6 & 30.4 & 1 & 141.4 \\
\hline
\end{tabular}

elements that were used in the data analysis, this occurred only for $\mathrm{Cu}$ (five personal measurements in Amsterdam and one in Helsinki) and $\mathrm{Ni}$ (six indoor measurements in Amsterdam and one in Helsinki).

\section{Statistical methods and data analysis}

We assessed the correlation between personal, indoor, and outdoor concentrations by means of individual regression analysis, using the models published previously, ${ }^{77}$ and investigated the distribution of the individual regression results. Medians are presented because most correlation and regression coefficients were not normally distributed (Shapiro-Wilk Statistic, $\mathrm{p}<0.05$ ). Although all subjects were non-smokers, participants could still be exposed to ETS elsewhere, or at home in the case of a smoking spouse or visitor. To investigate the influence of ETS on the relation between personal, indoor, and outdoor $\mathrm{PM}_{2.5}$, we conducted the same regression analyses after excluding days with ETS exposure. We excluded subjects with fewer than four remaining observations.

We performed additional analyses to estimate the (independent) contributions from outdoor and indoor air to personal exposure. This was achieved by including both indoor and outdoor concentrations as predictors of personal exposure in the same regression model:

$\mathrm{C}_{\text {personal, it }}=\alpha_{\mathrm{i}}+\beta \times \mathrm{C}_{\text {outdoors, }}+\gamma \times \mathrm{C}_{\text {indoors,it }}$ where $\mathrm{C}=$ concentration, $\mathrm{i}=$ subject $\mathrm{i}, \mathrm{t}=$ day.

Because of the small number of observations per subject and more than one explanatory variable in the model we did not specify individual multiple regression models, as in the previous analyses. The SAS procedure "proc mixed" was used to adjust regression results for correlations between repeated measurements. A random intercept model was used, as we did not expect any autocorrelation in the repeated measurements because measurements were conducted biweekly. We compared the results of individual regression analysis and the basic mixed model with models including an autoregressive covariance structure $(\operatorname{AR}(1))$. We found that the model that specified an AR( 1 ) yielded slopes and standard errors that were very similar to the results of the individual regression and random intercept model. Covariance parameter estimates for $\mathrm{AR}(1)$ were generally non-significant, consistent with the long approximately two week period in between successive measurements for the same individual. Addition of a random intercept for measurement date, to control for correlations between measurements that were conducted on the same day, also did not change the results (results not shown).

\section{RESULTS}

\section{Quality assurance and control}

Percentages of samples that were above the uncertainty limit and remained positive after subtraction of the median field blank are given in table 1. Elements for which the percentages detected were lower than $50 \%$ for all three types of samples in one of the cities ( $\mathrm{Br}, \mathrm{Cr}$, and $\mathrm{Ti}$ ) were excluded in further analyses.

Median field blank values were generally similar for the two cities and different types of samples. Median field blanks were generally low $(<10 \%)$ compared to the total amount measured for S, Zn, K, Ca, V, Si, and $\mathrm{Cl}$. High field blank values (>500 ng/filter) were found for $\mathrm{Pb}$ and $\mathrm{Al}$. Detailed information on field blanks is given elsewhere. ${ }^{24}$

Table 2 presents coefficients of variation (CV) of duplicates, as a measure of precision, calculated as the median of the absolute percentage difference between co-located pairs divided by $\sqrt{ } 2$. Only duplicates for which at least one of the individual concentrations were detected are included.

Coefficients of variation values were generally lowest for $S$ (median CV $<5 \%$ for all sample types). The poorest precision is found for outdoor duplicates in Helsinki, with median CV above $25 \%$ for nine out of the 13 elements. This low precision cannot readily be explained, especially since the precision of the personal duplicates appears to be better, despite the 2.5fold lower sampled volume. All outdoor duplicates in Helsinki were conducted in the same one week period, which might not be representative for the full study period. In addition, despite the low precision of the outdoor duplicates of especially the soil related elements in Helsinki, the correlation among these elements was still relatively high, with Spearman $r$ s among $\mathrm{Ca}, \mathrm{Si}$, and $\mathrm{Al}$ ranging from 0.81 to 0.88 (data not shown). Only $\mathrm{Pb}$ and $\mathrm{Al}$ showed a consistent pattern of generally low precision and were therefore excluded from further analyses. In addition, personal concentrations of $\mathrm{V}, \mathrm{Mn}$, and Ni were excluded for combined reasons of poor detection and low precision.

\section{Concentration levels and ratios}

Concentration levels are generally fairly similar in Amsterdam compared with Helsinki (table 3). In outdoor 


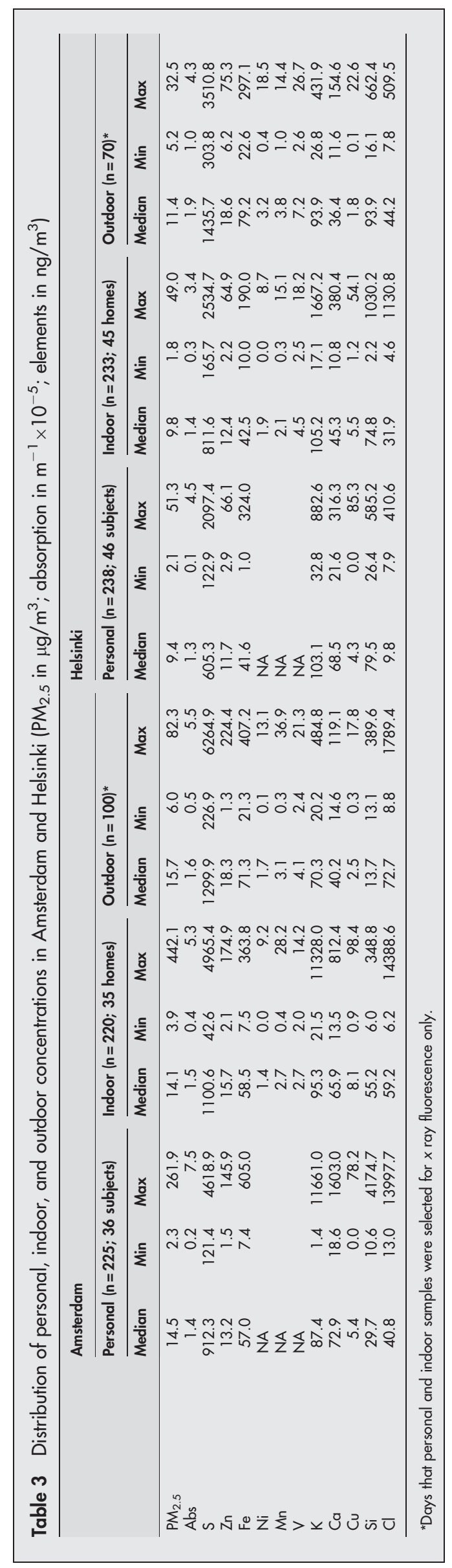

air, the biggest difference is found for $\mathrm{Si}$ (median $14 \mathrm{ng} / \mathrm{m}^{3}$ in Amsterdam compared to $94 \mathrm{ng} / \mathrm{m}^{3}$ in Helsinki). Indoor $\mathrm{Si}$ levels were more similar, however. In Amsterdam, some subjects had very high personal or indoor concentrations as a result of exposure to ETS. ETS exposure in the living room and elsewhere occurred on $13 \%$ and $16 \%$ of the selected samples, respectively, whereas for Helsinki only one observation with ETS exposure occurred. For both $\mathrm{PM}_{2.5}$ mass and most elements, excluding days with ETS exposure in Amsterdam resulted in a $5-15 \%$ reduction of median personal and indoor concentrations. The largest reduction was observed in personal $\mathrm{Cl}$, for which the median concentration decreases from 40.8 to $16.5 \mathrm{ng} / \mathrm{m}^{3}$. Correlations among the different elements are published elsewhere. ${ }^{24}$

Figure 1 presents the distributions of individual median personal/indoor/outdoor ratios $(\mathrm{n}=36$ in Amsterdam and $\mathrm{n}=46$ in Helsinki). As a ratio based on replacement values only is highly unreliable, we excluded ratios for which both the denominator and the numerator were below the uncertainty limit. Personal/outdoor and indoor/outdoor ratios for $\mathrm{PM}_{2.5}$ mass are below $\mathrm{l}$ and are similar for Amsterdam and Helsinki. For ABS, personal/outdoor and indoor/outdoor ratios are higher than those for $\mathrm{PM}_{2.5}$ (but still $<1$ ) in Amsterdam, and similar to those for $\mathrm{PM}_{2.5}$ in Helsinki. Personal/outdoor and indoor/outdoor ratios for $\mathrm{S}, \mathrm{Zn}, \mathrm{Fe}, \mathrm{Ni}$, $\mathrm{Mn}$, and $\mathrm{V}$ are also below 1 . In Amsterdam, personal/outdoor and indoor/outdoor ratios for these elements are similar to those for $\mathrm{PM}_{2.5}$ mass, whereas in Helsinki these ratios are smaller to those observed for $\mathrm{PM}_{2.5}$ mass. Personal/outdoor and indoor/outdoor ratios $>1$ are found for $\mathrm{Ca}, \mathrm{Cu}$ (both cities), and Si (Amsterdam only). Personal/indoor ratios are generally similar to those for $\mathrm{PM}_{2.5}$. Excluding days with ETS exposure in Amsterdam generally showed a small reduction in the overall median personal/outdoor and indoor/outdoor ratios. The variability in the individual median personal/ outdoor and indoor/outdoor ratios (fig 1), however, decreased substantially for some elements, especially for K, for which the $75 \%$ percentile decreased from 3.3 to 1.2 for personal/outdoor ratios and from 4.4 to 1.6 for indoor/ outdoor ratios.

\section{Relation between personal, indoor, and outdoor concentrations}

Personal, indoor, and outdoor $\mathrm{PM}_{2.5}$ concentrations were highly correlated (table 4; fig 2). Correlations between personal and outdoor $\mathrm{ABS}$ and $\mathrm{S}$ were higher and less variable than those for $\mathrm{PM}_{2.5}$ in both cities (median Spearman $r \geqslant 0.9$ ). High correlations were also found for $\mathrm{Zn}$ and Fe, especially in Amsterdam. Correlations for the remaining elements are generally lower compared to $\mathrm{PM}_{2.5}$ mass in both cities, with the poorest correlation observed for $\mathrm{Cu}$. Excluding observations with ETS exposure resulted in slightly higher median correlations for some components. The correlations between indoor and outdoor elemental concentrations were generally similar or slightly higher than observed for personal-outdoor concentrations. Indoor-outdoor correlations for $\mathrm{Ni}, \mathrm{Mn}$, and $\mathrm{V}$ (not adequately available for personal samples) are in the same order of magnitude to the ones for $\mathrm{PM}_{2.5}$ in Amsterdam, whereas they are somewhat lower in Helsinki. The correlations between personal and indoor elemental concentrations were in general high $(r \geqslant 0.80)$, with the exception of $\mathrm{Cu}, \mathrm{Ca}, \mathrm{Si}$ (Amsterdam), and Fe (Helsinki).

For $\mathrm{PM}_{2.5}$ mass concentrations, a median slope of the relation between personal/indoor and outdoor concentrations of about 0.5 is found in both cities (table 4). Personaloutdoor and indoor-outdoor slopes for ABS, S, and some of the transition metals ( $\mathrm{Zn}, \mathrm{Fe}$, and $\mathrm{Mn}$ ) are generally higher then those for $\mathrm{PM}_{2.5}$ in Amsterdam, whereas slopes for these components are similar to those for $\mathrm{PM}_{2.5}$ in Helsinki. For the 


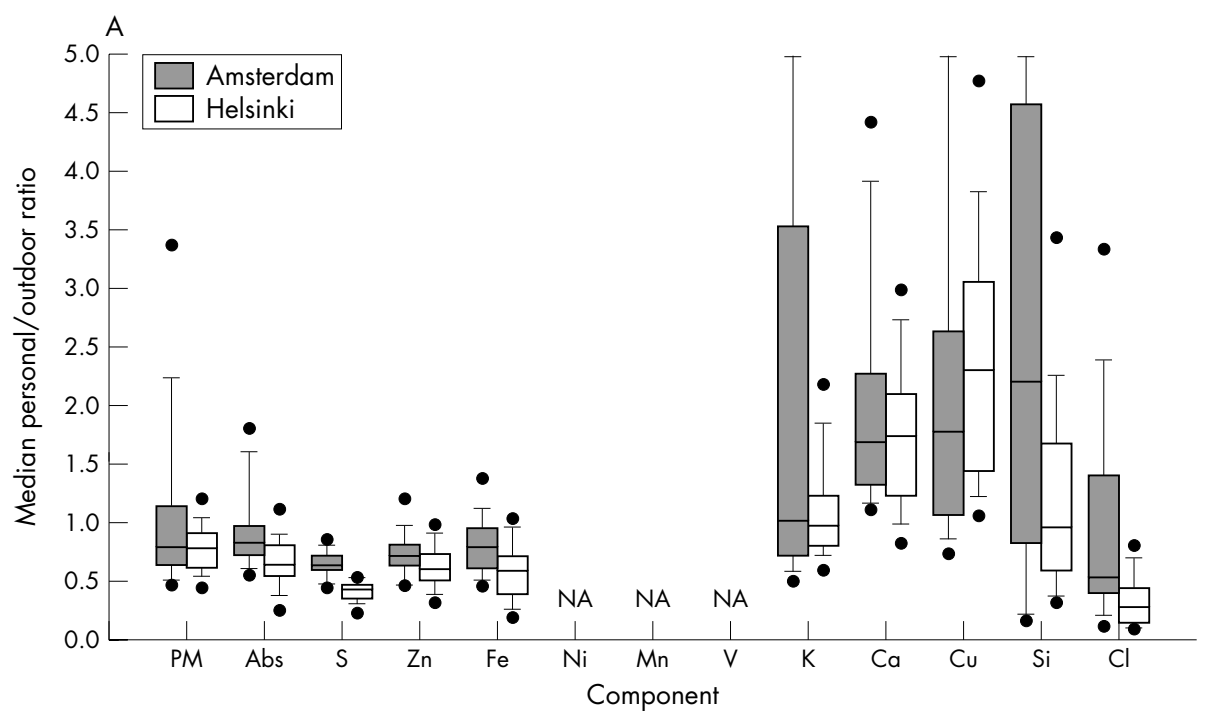

Figure 1 Distribution (5th, 10th, 25th, median, 75th, 90th, 95th percentiles) of individual median personal/outdoor ratios $(A)$, indoor/outdoor ratios $(B)$, and personal/indoor ratios $(C)$ in

Amsterdam and Helsinki.
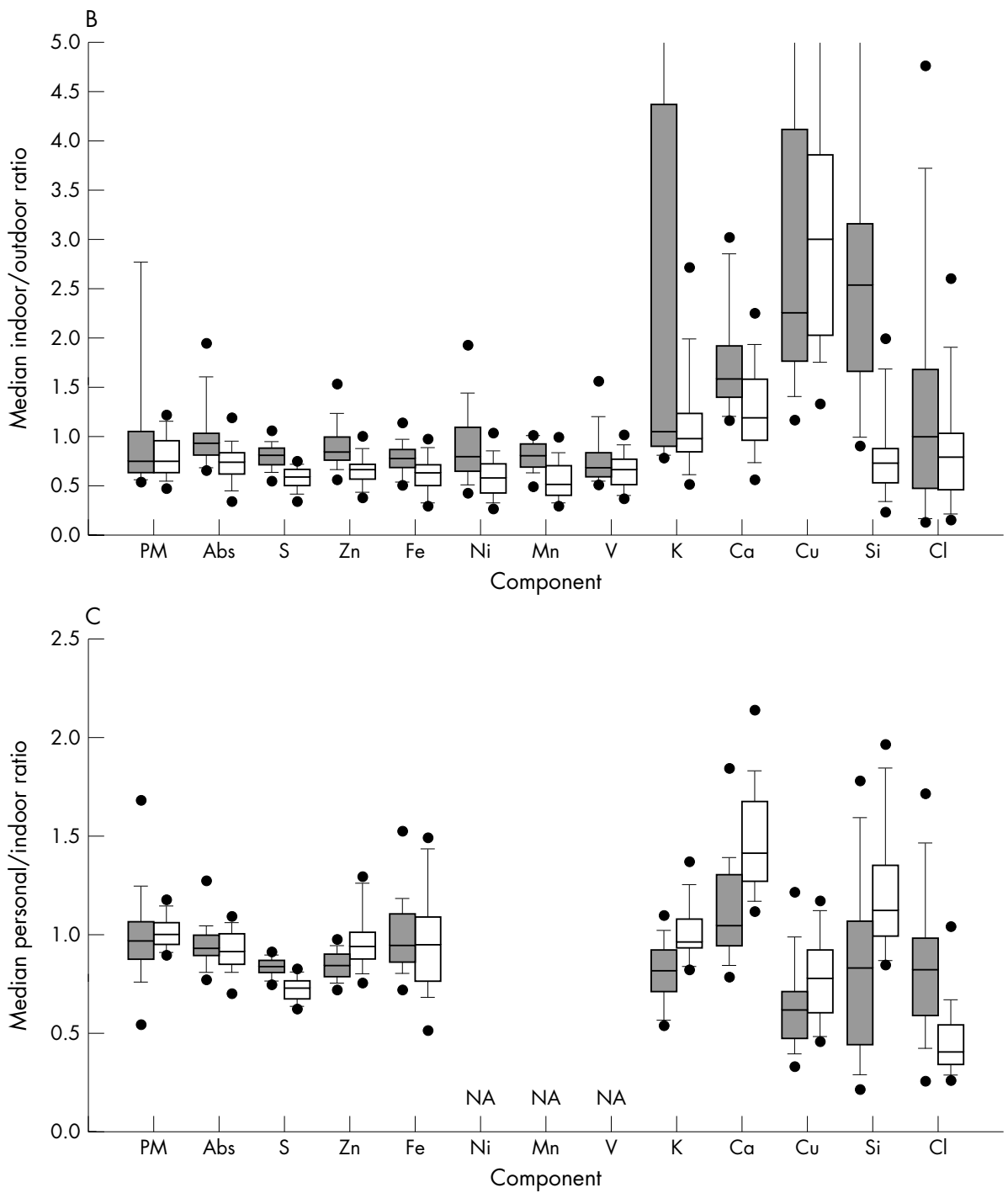

mentioned elements with higher slopes in Amsterdam, the highest values are found for the relation between personal/ indoor and outdoor ABS and for the relation between indoor and outdoor S. Consistently lower personal-outdoor and indoor-outdoor slopes compared to the ones found for $\mathrm{PM}_{2.5}$ mass are observed for $\mathrm{Cu}$. 


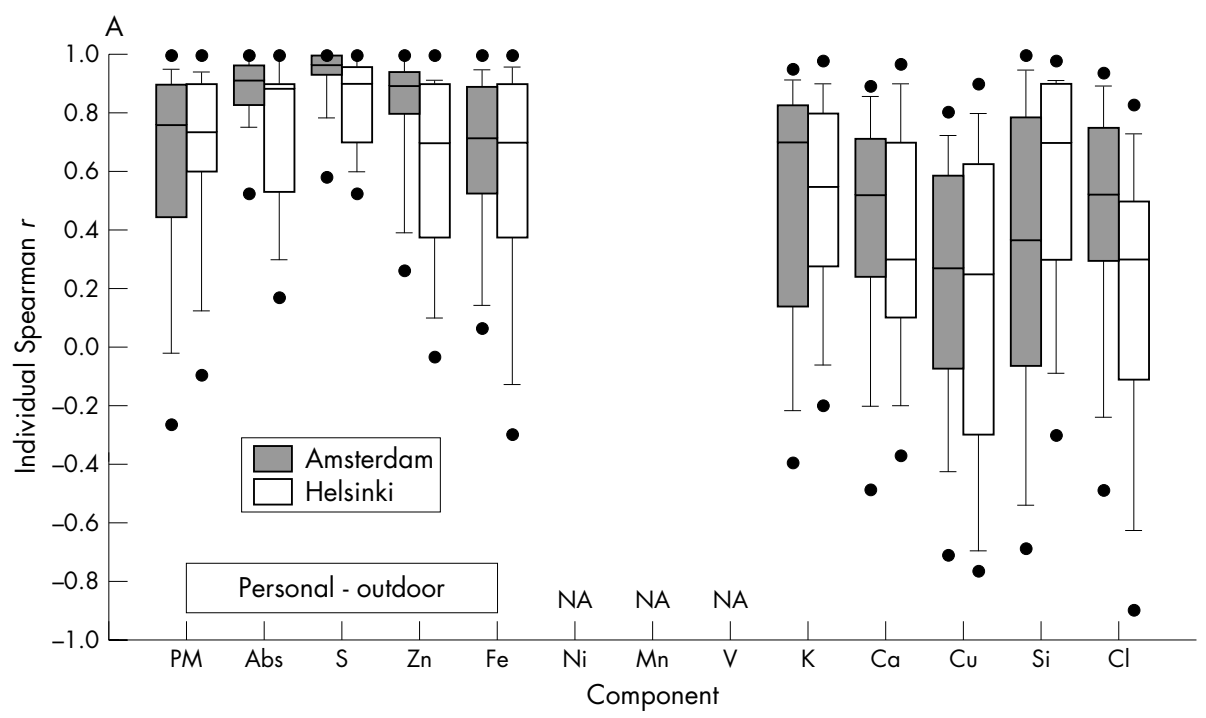

Figure 2 Distribution (5th, 10th, 25th, median, 75 th, 90 th, 95 th percentiles) of individual Spearman correlation coefficients between personal and outdoor concentrations (A), indoor and outdoor concentrations (B), and personal and indoor concentrations (C) for Amsterdam and Helsinki.
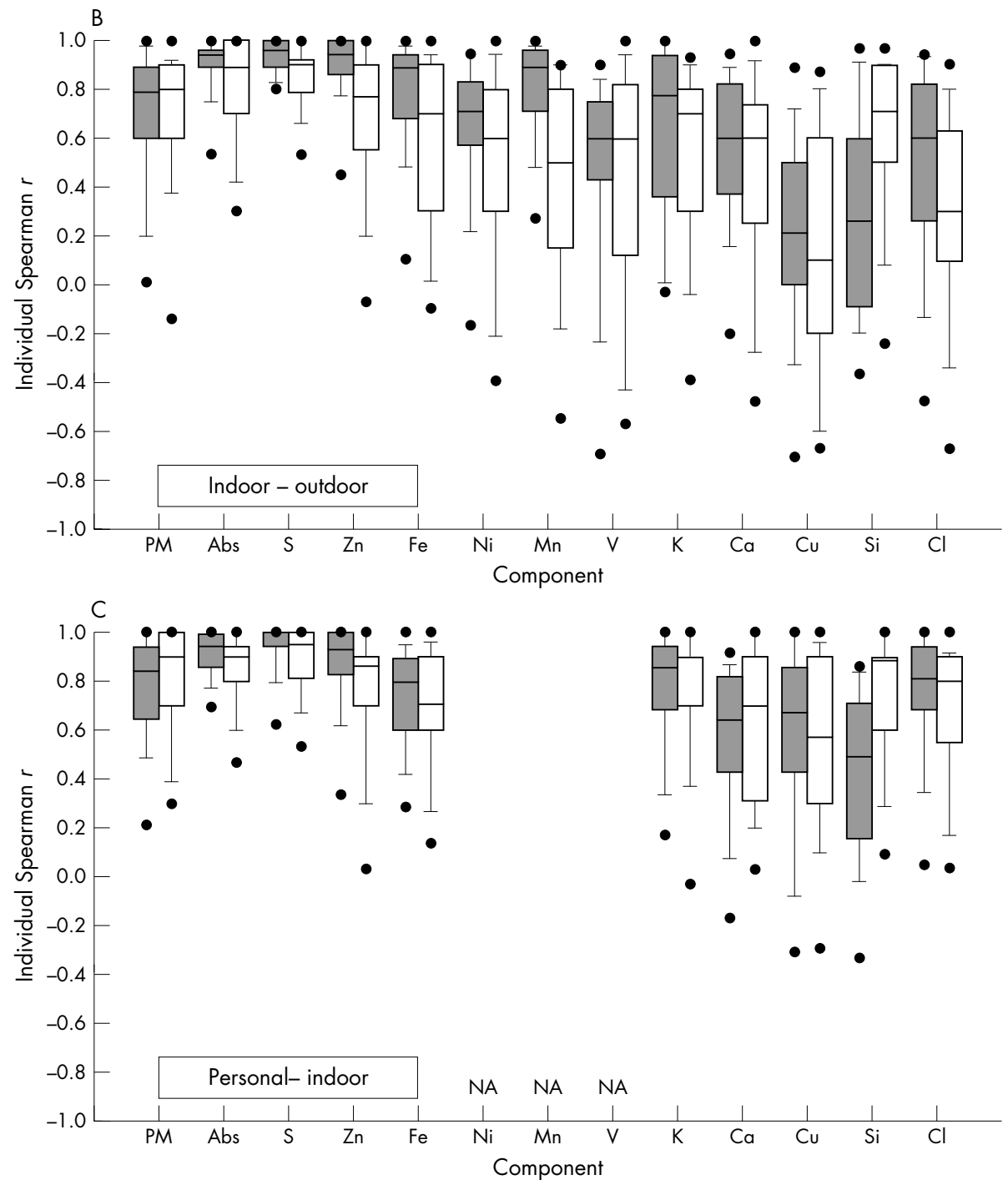

Independent contribution of indoor and outdoor air to personal exposure

The slopes in table 5 represent the independent contributions of indoor and outdoor air to personal exposure. For example, for non-ETS exposed subjects in Amsterdam a $10 \mu \mathrm{g} / \mathrm{m}^{3}$ change in indoor or outdoor $\mathrm{PM}_{2.5}$ will result in an 8.1 or $0.6 \mu \mathrm{g} / \mathrm{m}^{3}$ change, respectively, in personal exposure. It should be noted, however, that the $0.6 \mu \mathrm{g} / \mathrm{m}^{3}$ for outdoor air represents the independent contribution, that is the effect of outdoor air on personal exposure that is not through the 
Table 4 Median Spearman R and regression slopes of the relation between personal, indoor, and outdoor concentrations in Amsterdam and Helsinki

\begin{tabular}{|c|c|c|c|c|c|c|}
\hline & \multicolumn{3}{|c|}{ Amsterdam } & \multicolumn{3}{|l|}{ Helsinki } \\
\hline & $\begin{array}{l}\text { Personal- } \\
\text { outdoor } \\
(\mathrm{n}=36)\end{array}$ & $\begin{array}{l}\text { Indoor- } \\
\text { outdoor } \\
(\mathrm{n}=35)\end{array}$ & $\begin{array}{l}\text { Personal- } \\
\text { indoor } \\
(\mathrm{n}=35)\end{array}$ & $\begin{array}{l}\text { Personal- } \\
\text { outdoor } \\
(\mathrm{n}=46)\end{array}$ & $\begin{array}{l}\text { Indoor- } \\
\text { outdoor } \\
(\mathrm{n}=45)\end{array}$ & $\begin{array}{l}\text { Personal } \\
\text { indoor } \\
(n=45)\end{array}$ \\
\hline \multicolumn{7}{|c|}{ Spearman $r$} \\
\hline $\mathrm{PM}_{2.5}$ & 0.76 & 0.79 & 0.84 & 0.74 & 0.80 & 0.90 \\
\hline Abs & 0.91 & 0.94 & 0.94 & 0.89 & 0.89 & 0.90 \\
\hline $\mathrm{S}$ & 0.96 & 0.96 & 1.00 & 0.90 & 0.90 & 0.95 \\
\hline $\mathrm{Zn}$ & 0.89 & 0.94 & 0.93 & 0.70 & 0.77 & 0.86 \\
\hline $\mathrm{Fe}$ & 0.71 & 0.89 & 0.80 & 0.70 & 0.70 & 0.71 \\
\hline $\mathrm{Ni}$ & NA & 0.71 & NA & NA & 0.60 & NA \\
\hline $\mathrm{Mn}$ & NA & 0.89 & NA & NA & 0.50 & NA \\
\hline V & NA & 0.60 & NA & NA & 0.60 & NA \\
\hline $\mathrm{K}$ & 0.70 & 0.77 & 0.86 & 0.55 & 0.70 & 0.90 \\
\hline $\mathrm{Ca}$ & 0.52 & 0.60 & 0.64 & 0.30 & 0.60 & 0.70 \\
\hline $\mathrm{Cu}$ & 0.27 & 0.21 & 0.67 & 0.25 & 0.10 & 0.57 \\
\hline $\mathrm{Si}$ & 0.36 & 0.26 & 0.49 & 0.70 & 0.71 & 0.89 \\
\hline $\mathrm{Cl}$ & 0.52 & 0.60 & 0.81 & 0.30 & 0.30 & 0.80 \\
\hline \multicolumn{7}{|l|}{ Slope } \\
\hline $\mathrm{PM}_{2.5}$ & 0.46 & 0.46 & 0.95 & 0.48 & 0.53 & 0.93 \\
\hline Abs & 0.95 & 0.83 & 1.08 & 0.61 & 0.60 & 1.02 \\
\hline$S$ & 0.65 & 0.79 & 0.82 & 0.40 & 0.52 & 0.78 \\
\hline $\mathrm{Zn}$ & 0.55 & 0.64 & 0.80 & 0.37 & 0.42 & 0.88 \\
\hline $\mathrm{Fe}$ & 0.65 & 0.68 & 0.89 & 0.47 & 0.44 & 0.94 \\
\hline $\mathrm{Ni}$ & NA & 0.44 & NA & NA & 0.38 & NA \\
\hline $\mathrm{Mn}$ & NA & 0.69 & NA & NA & 0.36 & NA \\
\hline V & NA & 0.47 & NA & NA & 0.35 & NA \\
\hline $\mathrm{K}$ & 0.60 & 0.79 & 0.69 & 0.55 & 0.51 & 0.79 \\
\hline $\mathrm{Ca}$ & 0.73 & 0.55 & 0.81 & 0.64 & 0.50 & 1.05 \\
\hline $\mathrm{Cu}$ & 0.16 & 0.32 & 0.59 & 0.20 & 0.01 & 0.80 \\
\hline $\mathrm{Si}$ & 0.39 & 0.62 & 0.74 & 0.35 & 0.47 & 0.73 \\
\hline $\mathrm{Cl}$ & 0.53 & 0.60 & 0.93 & 0.00 & 0.08 & 0.31 \\
\hline
\end{tabular}

impact of outdoor air on indoor air. Both in Helsinki and Amsterdam, slopes for outdoor air in the model with indoor air included were much smaller than in the model with only outdoor air included. Comparison of the standard errors of the two models showed that multicollinearity was not a major problem. Outdoor air remained a significant predictor for personal exposure for most elements including ABS, S, $\mathrm{Zn}, \mathrm{K}$, and Ca. For $\mathrm{PM}_{2.5}$ only in Amsterdam a significant independent contribution of outdoor air was found.

\section{DISCUSSION}

In this study we found that personal and indoor $\mathrm{PM}_{2.5}$ mass and elemental concentrations are generally lower than and longitudinally highly correlated with ambient concentrations. In both cities, we found the highest correlations for $S$ and
ABS (median Spearman $r \geqslant 0.9$ ). Low correlations were found for Si (Amsterdam), $\mathrm{Ca}, \mathrm{Cu}$, and $\mathrm{Cl}$.

\section{Correlation between personal, indoor, and outdoor concentrations}

Several recent studies have investigated the longitudinal correlation between personal and outdoor $\mathrm{PM}_{2.5}$ concentrations. Of these studies, two were conducted among older subjects with COPD, ${ }^{10}{ }^{13}$ two among elderly ( $>64$ years of age) in Baltimore, MD, USA ${ }^{911}$ and one among children in the Netherlands. ${ }^{8}$ Correlations between personal, indoor, and outdoor $\mathrm{PM}_{2.5}$ in our study were lower than, or similar to those found in three of those studies ${ }^{811} 13$ and higher than those found in the other two studies. ${ }^{9}{ }^{10}$ In all studies, considerable variability in individual correlations was

\begin{tabular}{|c|c|c|c|c|c|c|c|c|c|c|c|c|}
\hline & \multicolumn{4}{|c|}{ Amsterdam, all observations } & \multicolumn{4}{|c|}{ Amsterdam, no ETS } & \multicolumn{4}{|c|}{ Helsinki, all observations } \\
\hline & \multicolumn{2}{|l|}{ Outdoor } & \multicolumn{2}{|l|}{ Indoor } & \multicolumn{2}{|c|}{ Outdoor } & \multicolumn{2}{|l|}{ Indoor } & \multicolumn{2}{|l|}{ Outdoor } & \multicolumn{2}{|l|}{ Indoor } \\
\hline & $\beta$ & SE & $\gamma$ & SE & $\beta$ & SE & $\gamma$ & SE & $\beta$ & SE & $\gamma$ & SE \\
\hline $\mathrm{PM}_{2.5}$ & $0.13^{*}$ & 0.08 & $0.54 \ddagger$ & 0.03 & $0.06 \ddagger$ & 0.02 & $0.81 \ddagger$ & 0.01 & -0.02 & 0.02 & $0.97 \ddagger$ & 0.03 \\
\hline$A B S$ & 0.07 & 0.05 & $1.04 \ddagger$ & 0.05 & $0.25 \ddagger$ & 0.07 & $0.77 \ddagger$ & 0.08 & $0.06 \dagger$ & 0.03 & $0.98 \ddagger$ & 0.04 \\
\hline $\mathrm{s}$ & $0.18 \ddagger$ & 0.04 & $0.59 \ddagger$ & 0.05 & $0.24 \ddagger$ & 0.04 & $0.51 \ddagger$ & 0.05 & $0.05 \dagger$ & 0.02 & $0.66 \ddagger$ & 0.04 \\
\hline $\mathrm{Zn}$ & $0.27 \ddagger$ & 0.03 & $0.39 \ddagger$ & 0.04 & $0.31 \ddagger$ & 0.03 & $0.35 \ddagger$ & 0.05 & $0.09 \ddagger$ & 0.03 & $0.81 \neq$ & 0.05 \\
\hline $\mathrm{Fe}$ & 0.07 & 0.09 & $0.78 \dagger$ & 0.13 & 0.04 & 0.10 & $0.81 \ddagger$ & 0.16 & 0.04 & 0.06 & $0.90 \ddagger$ & 0.10 \\
\hline $\mathrm{K}$ & -0.29 & 0.25 & $0.87 \ddagger$ & 0.02 & $0.15 \dagger$ & 0.06 & $0.62 \ddagger$ & 0.02 & $0.17 \ddagger$ & 0.04 & $0.57 \ddagger$ & 0.02 \\
\hline $\mathrm{Ca}$ & 0.23 & 0.46 & $0.78 \ddagger$ & 0.17 & 0.22 & 0.46 & $0.77 \dagger$ & 0.30 & $0.23 \ddagger$ & 0.07 & $0.84 \ddagger$ & 0.05 \\
\hline $\mathrm{Cu}$ & 0.06 & 0.12 & $0.56 \ddagger$ & 0.03 & 0.06 & 0.13 & $0.57 \ddagger$ & 0.03 & -0.12 & 0.17 & $0.79 \ddagger$ & 0.07 \\
\hline $\mathrm{Si}$ & -0.22 & 0.35 & $1.17 \ddagger$ & 0.37 & 0.03 & 0.12 & $0.81 \ddagger$ & 0.13 & $0.15 \ddagger$ & 0.03 & $0.44 \ddagger$ & 0.03 \\
\hline $\mathrm{Cl}$ & -0.03 & 0.04 & $0.95 \ddagger$ & 0.01 & 0.01 & 0.03 & $0.97 \ddagger$ & 0.02 & -0.01 & 0.02 & $0.37 \ddagger$ & 0.02 \\
\hline
\end{tabular}


observed, ranging from negative correlations to values close to 1.0 for individual subjects. This variability can partly be the result of low precision of the individual estimates, caused by the limited number of observations per person. Differences in correlation between subjects (and between different study populations) can be caused by differences in home air exchange rates, indoor sources, time activity patterns and the range in concentrations.

The higher correlations we observed for S are consistent with the results of some other studies that included measurements of sulfate, two of which also observed very high correlations (median $r>0.9$ ). ${ }^{10}{ }^{25} \mathrm{~A}$ cross sectional study among 21 cardiovascular patients in Saint John, New Brunswick, Canada also documented a very high correlation between daytime personal and outdoor sulfate $(r=0.95) .^{26}$ The high correlations for $\mathrm{S}$ and ABS can be explained by fewer indoor sources for these components and (for $S$ ) smaller spatial variation of outdoor air pollution. The correlations for $\mathrm{S}$ document that the correlation between outdoor concentrations and personal exposure to particles of ambient origin is even higher than for $\mathrm{PM}_{2.5}$. This conclusion is valid only for particles with the same size distribution as sulfate, since particle size determines penetration in the home. The high correlations for ABS document that this also applies for particulate matter from diesel vehicles, as other known outdoor sources of elemental carbon, such as wood smoke or coal fly ash, ${ }^{27}$ are probably of minor importance in the urban areas studied in our study.

When comparing the median Spearman $r$ for the different elements to the ones observed for $\mathrm{PM}_{2.5}$ mass, three main groups of components can be seen: elements with higher correlations between personal/indoor and outdoor concentrations compared to $\mathrm{PM}_{2.5}$ ( $\mathrm{S}$ and $\mathrm{ABS}$ in both cities, $\mathrm{Zn}$ in Amsterdam only); elements with correlations similar to those observed for $\mathrm{PM}_{2.5}$ (Fe, Ni, Mn, V in both cities, $\mathrm{Zn}$ and $\mathrm{Si}$ in Helsinki) and elements with lower correlations compared to $\mathrm{PM}_{2.5}$ ( $\mathrm{Si}$ in Amsterdam, $\mathrm{K}, \mathrm{Ca}, \mathrm{Cu}$, and $\mathrm{Cl}$ in both cities). The first group represents fine mode particles of mainly outdoor origin, with few indoor sources; the second group consists primarily of transition metals with variable sources, and the last group includes the soil and marine related elements, which represent the coarser part of the $\mathrm{PM}_{2.5}$ particles. With the exception of $\mathrm{Cl}$, elements of the last group also showed increased personal and/or indoor concentrations compared with outdoor concentrations, suggesting that the lower correlations for these elements are due to the influence of indoor sources. Larger spatial variability in outdoor concentrations may play a role as well.

In contrast to the growing number of studies on the time series correlation between personal and outdoor particulate matter mass concentrations, few other studies have investigated these correlations for elemental concentrations or ABS. In the study in a retirement facility in Baltimore, elemental concentrations were used to calculate two summary variables: a SOIL variable calculated as the sum of the oxides of crustal elements ( $\mathrm{Si}, \mathrm{Ca}, \mathrm{Fe}, \mathrm{Ti}$ ), and a trace element oxides (TEO) variable calculated as the sum of other atmospheric metal oxides. The correlations between personal, indoor, and outdoor concentrations for these summary variables were lower (median Pearson $r<0.5$ for TEO and $<0.1$ for SOIL) than observed for most individual elements of the same groups in our study. For $\mathrm{PM}_{2.5}$ mass and sulfate, correlations were similar to our results (median Pearson $r=0.82$ for $\mathrm{PM}_{2.5}$ and $0.92-0.95$ for sulfate), ${ }^{25}$ indicating that the general pattern of high correlations for sulfate and low correlations for soil related elements is consistent. In the EXPOLIS study, a population based study on $\mathrm{PM}_{2.5}$ exposures of the adult, urban population in six European countries, cross sectional correlations between personal and outdoor concentrations reported for Basel, Switzerland, were also high for S and weak for $\mathrm{Ca}$ (as an indicator for crustal particles). ${ }^{28}$ In addition, indoor ABS, measured in four of the EXPOLIS cities (Athens, Basel, Helsinki, and Prague) were highly correlated with outdoor levels. ${ }^{29}$

\section{Personal, indoor, and outdoor concentration levels}

Some other studies on personal $\mathrm{PM}_{2.5}$ concentrations have also found lower personal compared with outdoor concentrations, ${ }^{911}$ whereas others documented increased personal $\mathrm{PM}_{2.5}$ exposures. ${ }^{81013}$ For most elements, personal and indoor concentrations were also lower than outdoor concentrations, with the exception of $\mathrm{K}, \mathrm{Cu}$, and $\mathrm{Ca}$ in both cities and $\mathrm{Si}$ in Amsterdam. Median indoor/outdoor ratios of $\mathrm{PM}_{2.5}$ mass and elemental concentrations in Helsinki were generally similar to those observed in Helsinki in the EXPOLIS study. ${ }^{30}$ For example, the median indoor/outdoor ratio in the EXPOLIS study in the winter season was 0.77 for $\mathrm{PM}_{2.5}$ mass, 0.60 for $S$, and 0.65 for black smoke, compared with 0.79 , 0.61 , and 0.75 , respectively, for $\mathrm{PM}_{2.5}, \mathrm{~S}$, and ABS in Helsinki in our study. In the study in the retirement facility in Baltimore, personal (mean $13 \mu \mathrm{g} / \mathrm{m}^{3}$ ) and indoor (mean $10 \mu \mathrm{g} / \mathrm{m}^{3}$ ) were much lower than outdoor (mean $21 \mu \mathrm{g} / \mathrm{m}^{3}$ ) $\mathrm{PM}_{2.5}$ concentrations. For sulfate a similar pattern was found. Indoor and personal SOIL concentrations, however, were $10-20 \%$ higher than outdoor concentrations, whereas for TEO personal, indoor, and outdoor concentration were similar. When evaluating the slopes of the regression equations instead of the personal/indoor/outdoor ratios, slopes of the relation between personal and outdoor or between indoor and outdoor concentrations were similar for $\mathrm{PM}_{2.5}$, sulfate and TEO concentrations, with median slopes ranging from 0.38 to 0.46 for the different components and models. For SOIL concentrations, however, median slopes were much lower $(0.05-0.12) .{ }^{25}$ These results are in line with the finding of our study of comparable personal/indooroutdoor slopes for $\mathrm{S}$ and the transition metals, and a higher influence of indoor generated particles for the soil related elements.

Median outdoor $\mathrm{PM}_{2.5}$ mass concentrations were about 40\% higher in Amsterdam compared with Helsinki. This difference was not reflected in higher elemental concentrations in Amsterdam, however. The small difference in ABS is consistent with the fact that "soot" in current day Western European cities is mostly related to traffic emissions, especially diesel engines. In the PEACE study, outdoor $\mathrm{PM}_{10}$ concentrations measured in the winter of 1993/1994 were also about twofold higher in Amsterdam than in Kuopio, Finland, whereas black smoke concentrations were similar. $^{31}$ Part of the higher PM levels in Amsterdam could possibly be due to higher nitrate concentrations, a result of the high ammonia levels in the Netherlands resulting from intensive livestock farming.

\section{Independent contributions of indoor and outdoor air to personal exposure}

When indoor and outdoor air concentrations were included simultaneously in one linear regression model to explain personal exposure, substantially higher slopes were found for indoor air. The slopes for outdoor air were much smaller compared with the slopes without indoor concentrations in the model. This should not be interpreted to imply that outdoor air has only very little effect on personal exposure, as indoor and outdoor concentrations were highly correlated which we interpret as a result of penetration of outdoor air in the home. The regression model with both indoor and outdoor concentrations in the model only shows the independent contribution of outdoor air to personal exposure, that is the effect of outdoor air on 24 hour average personal 
Main messages

- Personal and indoor daily $\mathrm{PM}_{2.5}$ mass concentrations for elderly with cardiovascular disease in two European cities (Amsterdam and Helsinki) were lower than and highly correlated with outdoor concentrations.

- The correlations between personal and outdoor concentrations for $S$ and $A B S$ were higher than for $\mathrm{PM}_{2.5}$, indicating that personal exposure to $\mathrm{PM}_{2.5}$ of ambient origin is even more closely associated with outdoor $\mathrm{PM}_{2.5}$.

- Low correlations were observed for elements that represent the coarser part of the $\mathrm{PM}_{2.5}$ particles and/ or can have important indoor sources ( $\mathrm{Ca}, \mathrm{Cu}, \mathrm{Si})$.

exposure that is not through the impact of outdoor air on indoor air. The results are thus consistent with the notion that most of the contribution of outdoor air to personal exposure is through its contribution to indoor air. Direct effects on personal exposure are much smaller. This is consistent with the short time spent outdoors for this population (about 1 hour/day). One implication of this finding is that factors that influence indoor/outdoor relations such as home air exchange rate can have a large effect on personal exposures. Another implication is that exposure assessment should include characterisation of home address (indoor and outdoor) concentrations.

\section{Generalisability and limitations}

Comparison of the correlation between personal and outdoor concentrations in our current study with those reported in the literature suggests that we cannot expect that the exact quantitative values we found can be transferred directly to other locations and populations. We do expect that the major conclusions drawn from the correlation patterns hold in many other current day Western populations as well. This refers to the high longitudinal correlation between personal and outdoor $\mathrm{PM}_{2.5}$ supporting the use of outdoor concentrations as an exposure estimate in time series studies; the very high correlation between personal and outdoor S; and the generally high correlation between personal and indoor elemental concentrations. The broadly similar patterns we observed in Amsterdam and Helsinki, in spite of the differences in climate, ETS exposure, and frequency of the use of gas for cooking, support this statement.

For the interpretation of our results, the following features are important. Firstly, the study population consisted of subjects with CVD who are probably at higher risk to respond to ambient air pollution. Secondly, subjects spent a large amount $(88 \%)$ of their time in their own home. Thirdly, all subjects were non-smokers but especially in Amsterdam ETS exposure was relatively frequent. Fourthly, personal exposure monitoring was mostly conducted in the winter season, when air exchange rates are presumably low, especially in Finland. Low air exchange rates have been shown to result in lower correlations between outdoor and indoor air. Fifthly, subjects lived within a $2-4 \mathrm{~km}$ radius of the central monitoring site. We do not expect that this relatively small area has increased the personal-outdoor correlation substantially, especially for $\mathrm{PM}_{2.5}$ and components that are mostly associated with the fine particle fraction and have little spatial variation. Finally, Amsterdam and Helsinki are both large cities with few large industrial sources within the built up area. In both cities altitude differences do not play a role. In more complex cities with large local sources, spatial variation of outdoor air
Policy implications

- The study shows that short term increases in outdoor fine particles are reflected in increased personal exposures, and also for potentially susceptible subjects who spend most of their time indoors.

- Studies investigating the short term effects of outdoor fine particles (time series studies, panel studies) can therefore rely on outdoor concentrations as a measure of exposure.

- The high correlation for $\mathrm{ABS}$ shows that, for the urban areas included in our study, this applies to particulate matter from combustion sources such as diesel vehicles as well.

pollution may be more substantial. In this case it can be expected that the correlation of outdoor air pollution measured at one central site with personal (and home outdoor) concentration is lower.

\section{CONCLUSIONS}

This study has shown that personal, indoor, and outdoor $\mathrm{PM}_{2.5}$ concentrations are highly correlated in cardiovascular patients in two European cities. The correlation for specific components of $\mathrm{PM}_{2.5}$ ( $\mathrm{S}$ and $\mathrm{ABS}$ ) were higher than for $\mathrm{PM}_{2.5}$, indicating that personal exposure to ambient origin $\mathrm{PM}_{2.5}$ is even more closely associated with outdoor $\mathrm{PM}_{2.5}$. The results of this study together with the results of other recent studies have documented that short term increases in outdoor air pollution are reflected in increased personal exposures, also for potentially susceptible subjects who (because of their illness) spend most of their time indoors. The findings of this study provide further support for using fixed site measurements as a measure of exposure to particulate matter in time series studies linking the day to day variation in particulate matter to the day to day variation in health endpoints, especially for components of particulate matter that are generally associated with fine mode particles and have few indoor sources. The high correlation for ABS documents that, for non-smoking elderly living in the urban areas included in our study, this applies to particulate matter from combustion sources such as diesel vehicles as well.

\section{ACKNOWLEDGEMENTS}

Research described in this article is conducted under contract (research agreement \#98-16) to the Health Effects Institute (HEI), an organisation jointly funded by the United States Environmental Protection Agency (EPA) (Assistance agreement R82811201) and automotive manufacturers. The content of this article does not necessarily reflect the views of HEI, nor does it necessarily reflect the views and policies of EPA, or motor vehicle and engine manufacturers.

\section{Authors' affiliations}

N A H Janssen, G Hoek, J J de Hartog, B Brunekreef, Division of Environmental and Occupational Health, Institute for Risk Assessment Sciences (IRAS), Utrecht University, the Netherlands

N A H Janssen, National Institute for Public Health and the Environment (RIVM), Center for Environmental Health Research, Bilthoven, the Netherlands

T Lanki, M Vallius, J Pekkanen, Environmental Epidemiology Unit, National Public Health Institute (KTL), Kuopio, Finland

R Van Grieken, Department of Chemistry, University of Antwerp, Antwerp, Belgium

J Pekkanen, Department of Public Health and General Practice, University of Kuopio, Finland 
The study was carried out in the framework of the ULTRA study (EU contract ENV4-CT97-0568). In Finland, additional funding came from Academy of Finland (research agreements \#42625 and \#102345).

The authors declare that they have no competing interest.

\section{REFERENCES}

1 Dockery DW, Pope CA III. A review of the acute respiratory effects of particulate air pollution. Annu Rev Public Health 1994;15:101-32.

2 Schwartz J. Air pollution and daily mortality: a review and meta-analysis. Environ Research 1994:64:36-52.

3 Brunekreef B, Dockery DW, Krzyzanowski M. Epidemiologic studies of health effects of low levels of major ambient air pollution components. Environ Health Perspect 1995; 103(suppl 2):3-13.

4 Ozkaynak H, Xue J, Spengler J, et al. Personal exposure to airborne particles and metals: Results from the particle team study in Riverside, California, J Exp Anal Environ Epidemiol 1996;6:57-78.

5 Wallace L. Indoor particles: A review. J Air Waste Manage Assoc 1996;46:98-126.

6 Janssen $\mathrm{NAH}$, Hoek $\mathrm{G}$, Harssema $\mathrm{H}$, et al. Childhood exposure to $P M_{10}$ : relation between personal, classroom and outdoor concentrations. Occup Environ Med 1997;54:888-94.

7 Janssen NAH, Hoek G, Brunekreef $B$, et al. Personal sampling of $\mathrm{PM}_{10}$ among adults: relation between personal, indoor and outdoor concentrations. Am J Epidemiol 1998;147:537-47.

8 Janssen NAH, Hoek G, Harssema H, et al. Personal exposure to fine particles in children correlates closely with ambient fine particles. Arch Environ Health 1999;54:95-101.

9 Sarnat JA, Koutrakis P, Suh HH. Assessing the relationship between personal particulate and gaseous exposures of senior citizens living in Baltimore, $M D$. J Air Waste Manage Assoc 2000;50:1184-98.

10 Ebelt ST, Petkau AJ, Vedal S, et al. Exposure of chronic obstructive pulmonary disease patients to particulate matter: Relationship between personal and ambient air concentrations. J Air Waste Manage Assoc 2000;50:1081-94.

11 Williams R, Suggs J, Zweidinger R, et al. The 1998 Baltimore Particulate Matter Epidemiology-Exposure Study: Part I. Comparison of ambient, residential outdoor, indoor and apartment particulate matter monitoring. $J$ Expo Anal Environ Epidemiol 2000;10:518-32.

12 Williams R, Suggs J, Creason J, et al. The 1998 Baltimore Particulate Matter Epidemiology-Exposure Study: Part 2. Personal exposure assessment associated with an elderly study population. J Expo Anal Environ Epidemiol 2000; 10:533-43.

13 Rojas-Bracho L, Suh HH, Koutrakis P. Relationship among personal, indoor, and outdoor fine and coarse particle concentrations for individuals with COPD. J Expo Anal Environ Epidemiol 2000;3:294-306.

14 Wilson WE, Suh HH. Fine particles and coarse particles: concentration relationships relevant to epidemiologic studies. J Air Waste Manag Assoc 1997;47:1238-49.
15 US EPA. Air quality criteria for particulate matter (third external review draft). 2002 http://cfpub.epa.gov/ncea/cfm/partmatt.cfm?ActType = default (accessed 5 September 2005)

16 Laden F, Neas LM, Dockery DW, et al. Association of fine particulate matter from different sources with daily mortality in six U.S. cities. Environ Health Perspect 2000;108:941-7.

17 Janssen NAH, de Hartog JJ, Hoek G, et al. Personal exposure to fine particulate matter in elderly subjects: relation between personal, indoor, and outdoor concentrations. J Air Waste Manag Assoc 2000;50:1133-43.

18 Pekkanen J, Timonen KL, Tiittanen P, et al. ULTRA: Exposure and risk assessment for fine and ultrafine particles in ambient air. Study manual and data book. KTL Report B9/2000 (http://www.ktl.fi/ultra).

19 Janssen NAH, Vliet PHN van, Aarts FJH, et al. Assessment of exposure to traffic related air pollution of children attending schools near motorways. Atmos Environ 2001;35:3875-84.

20 ISO 9835. 1993. Ambient air-Determination of a black smoke index.

21 OECD. 1964. Methods of measuring air pollution. Organization for Economic Cooperation and Development, Paris.

22 Edwards JD, Ogren JA, Weiss RE, et al. A comparison of British smoke with optical absorption coefficient and elemental carbon concentrations. Atmos Environ 1983;17:2337-41.

23 Samek L, Injuk J, Van Espen P, et al. Performance of a new compact EDXRF spectrometer for aerosol analysis. X-Ray Spectrometry 2002;31:84-6.

24 Brunekreef B, Janssen NAH, de Hartog J. Personal, indoor and outdoor exposures to PM2.5 and its components for groups of cardiovascular patients in Amsterdam and Helsinki, Research Report 127. Health Effects Institute, Boston, MA.

25 Landis MS, Norris GA, Williams RW, et al. Personal exposures to $\mathrm{PM}_{2.5}$ mass and trace elements in Baltimore, MD, USA. Atmos Environ 2001;35:6511-24

26 Stieb DM, Brook JR, Broder I, et al. Personal exposure of adults with cardiorespiratory disease to particulate acid and sulfate in Saint John, New Brunswick, Canada. Appl Occup Environ Hyg 1998;13:461-8.

27 Schaver JJ. Evaluation of elemental carbon as a marker for diesel particulate matter. J Expo Anal Environ Epidemiol 2003;13:443-53.

28 Oglesby L, Kunzli N, Roosli M, et al. Validity of ambient levels of fine particles as surrogate for personal exposure to outdoor air pollution-results of the European EXPOLIS-EAS study (Swiss Center Basel). J Air Waste Manage Assoc 2000;50:1251-61.

29 Gotschi T, Oglesby L, Mathys P, et al. Comparison of black smoke and PM2.5 levels in indoor and outdoor environments of four European cities. Environ Sci Technol 2002;36:1191-7.

30 Koistinen KJ, Edwards RD, Mathys P, et al. Sources of PM2.5 in personal exposures and residential indoor, outdoor and workplace microenvironments in EXPOLIS-Helsinki, Finland. Scand J Work Environ Health 2004;30(suppl 2):36-46.

31 Hoek G, Forsberg B, Borowska $M$, et al. Wintertime $P_{10}$ and black smoke concentrations across Europe: Results from the PEACE study. Atmos Environ 1997;31:3609-22. 